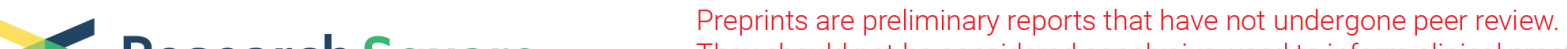 Research Square They should not be considered conclusive, used to inform clinical practice, or referenced by the media as validated information.
}

\section{The effect of a 5-year hand hygiene initiative, consisting of the 5 Components, the 5 Steps, and the Hand Hygiene Self-Assessment Framework, an interrupted time-series study.}

Yumi Suzuki ( $\square$ yumiatwork@me.com )

NHO Shimoshizu Hospital https://orcid.org/0000-0002-3601-6157

Motoko Morino

NHO Shimoshizu National Hospital

Ichizo Morita

Japanese Red Cross Toyota College of Nursing

Shigenori Yamamoto

NHO Shimoshizu National Hospital

\section{Research}

Keywords: Infection prevention, Hand hygiene, Multimodal initiative, Guideline adherence

Posted Date: February 3rd, 2020

DOl: https://doi.org/10.21203/rs.2.22453/v1

License: (c) (1) This work is licensed under a Creative Commons Attribution 4.0 International License.

Read Full License

Version of Record: A version of this preprint was published at Antimicrobial Resistance and Infection Control on May 27th, 2020. See the published version at https://doi.org/10.1186/s13756-020-00732-7. 


\section{Abstract}

\section{Background:}

A World Health Organization (WHO) guideline-based multimodal hand hygiene $(\mathrm{HH})$ initiative consisting of the 5 Components, the 5 Steps, and the HH Self-Assessment Framework (HHSAF) was introduced hospital-wide to a nonteaching Japanese hospital for 5 years. The objective of this study was to assess the effect of this initiative in terms of changes in alcohol-based hand rub (ABHR) consumption and HHSAF score.

\section{Methods:}

The consumption of monthly hospital-wide ABHR was calculated as ml per patient day (PD). The change in ABHR consumption was analysed by an interrupted time series analysis, with a preintervention period of 36 months and an intervention period of 60 months. The correlation between annual ABHR consumption and the HHSAF score was estimated using Pearson's correlation coefficients.

\section{Results:}

A statistically significant increase was found in the monthly ABHR consumption (change in slope: + $0.479 \mathrm{ml} / \mathrm{PD}, \mathrm{p}<0.01$ ). Annual ABHR consumption was strongly correlated with the annual HHSAF score $(r=0.971, p<0.01)$.

\section{Conclusions:}

A 5-year, 5-step, WHO-based HH initiative significantly increased ABHR consumption. Our study suggested that the HHSAF score can be a good process measure to improve $\mathrm{HH}$ in a single facility, as ABHR consumption increased with the HHSAF score.

\section{Background}

Hand hygiene $(\mathrm{HH})$ plays a key role in preventing hospital-acquired infections, as it prevents the spread of infectious organisms from patient to patient through the contamination of healthcare workers' hands [13]. The World Health Organization (WHO) published a multimodal strategy to improve hand hygiene adherence in 2009 [4], and improved $\mathrm{HH}$ has been reported from several areas with national and subnational $\mathrm{HH}$ campaigns based on the WHO guidelines [3,5-7]. However, there were no active national or sub-national initiatives in Japan, and $\mathrm{HH}$ adherence in Japanese hospitals was reported to be very low [8]. Additionally, long-term care facilities have shown very low $\mathrm{HH}$ adherence global, which is in serious need of improvement [9-10].

The WHO multimodal HH strategy includes 3 main concepts: the "My 5 Moments for Hand Hygiene" approach, the "Five Components of the WHO Multimodal HH Improvement Strategy" (the 5 Components), and the "stepwise approach" [11]. The "My 5 Moments for Hand Hygiene" approach highlights indications 
for moments for $\mathrm{HH}$. The 5 Components refer to the implementation of multiple actions to tackle different obstacles and behavioural barriers to improving $\mathrm{HH}$. These include (1) system change, (2) training and education, (3) evaluation and feedback, (4) reminders in the workplace, and (5) promotion of an institutional safety climate. The stepwise approach helps to develop and plan the hand hygiene improvement programme over time, which is based on a rational sequence of activities. This includes the "5 Steps": (1) facility preparedness, (2) baseline evaluation, (3) implementation, (4) follow-up evaluation, and (5) ongoing planning and review cycle. As the original concept of the WHO strategy is intended to make improvements in $\mathrm{HH}$ sustainable, not to be used as a single campaign, the " 5 Steps" cycle is recommended to be repeated for 5 years [11]. Some previous studies have reported the results from adopting some parts of this strategy, the majority of which focused only on the "My 5 Moments for Hand Hygiene" approach and the 5 Components [12], while several focused only on the "stepwise approach" $[13,14]$. In spite of the original recommendations in the guideline, however, no studies were found that implemented both the " 5 Components" and the " 5 Steps" approaches for 5 consecutive years.

The Hand Hygiene Self-Assessment Framework (HHSAF) [15] is a validated, systematic tool with which a situational analysis of hand hygiene promotion and practices in each health-care facility can be obtained [16]. HHSAF acts as a diagnostic tool, identifying key issues requiring attention and improvement. Repeated use of HHSAF will also allow visualization of progress over time [15]. This tool has now been adopted in more than 90 countries [17]. We recorded our annual HHSAF scores for 5 years, which enabled us to visualize our progress over time and to analyse the correlation of the score with $\mathrm{HH}$ adherence.

We decided to introduce an $\mathrm{HH}$ initiative following the WHO HH strategy as a whole, including the 5 Steps and the HHSAF in our hospital, in which no systematic measures on $\mathrm{HH}$ had been implemented before.

The aim of this study was to assess the effect of a hospital-wide WHO-based $\mathrm{HH}$ initiative for 5 years. We also examined the correlation between the HHSAF score and alcohol-based hand rub (ABHR) consumption as an exploratory analysis.

\section{Methods}

\section{Design (Data collection)}

The HH initiative started in April 2014 and continued for 5 years until March 2019. The preintervention period was from April 2011 to March 2014 (36 months), and the intervention period was from April 2014 to March 2019 (60 months).

Monthly and annual ABHR consumption ( $\mathrm{ml}$ per patient day; $\mathrm{ml} / \mathrm{PD}$ ) was calculated by dividing the total amount of ABHR delivered from the pharmacy, hospital-wide, by the corresponding periods' patient census (patient hospitalization days). Monthly alcohol-based hand rub consumption and patient hospitalization days are shown in the Supplementary file. ABHR consumption data were collected from April 2014 to March 2019 each month in a prospective manner, and data from April 2011 to March 2014 were collected retrospectively. 
The annual HHSAF score was calculated at the end of each fiscal year from 2013 to 2019. Scores for 2011 and 2012 were calculated retrospectively. The same infection control nurse (ICN) and infection control doctor (ICD), both in charge of the hospital-wide $\mathrm{HH}$ initiative, confirmed the scores together throughout the study period.

\section{Settings}

The study was conducted in the 440-bed NHO Shimoshizu National Hospital, located in Chiba, Japan. This hospital is not a typical 'teaching hospital', except for some specialties that have limited teaching functions. Four wards, with a total of 200 beds (internal medicine, neurology, paediatrics, general surgery, neurosurgery, and orthopaedics), are mainly for secondary care (mean length of stay: 9.4 to 20.0 days). The proportion of private rooms is between 42.9 and $66.6 \%$. Five wards, with a total of 240 beds, provide long-term care mainly for patients with muscular dystrophies (120 beds, mean length of stay: 181.9 to 898.6 days) or patients with severe motor and intellectual delays (120 beds, mean length of stay: 99.5 to 202.1 days). The proportion of private rooms is between 30.0 and $42.9 \%$. The characteristics of these wards are similar to those of a paediatric long-term care facility rather than nursing homes for the elderly. Many patients have complex, chronic medical conditions and require heavy medical care, such as mechanical ventilation and/or tube feeding. They reside in these wards for years, often for their entire lives. On average, over a hundred patients a day required ventilators (including non-invasive positive pressure ventilators used only overnight) during the study period, although there are no intensive care unit (ICU) beds in the hospital. Patients in the long-term care wards had direct contact with several recreational staff members every day, in addition to clinical staff for medical care. The ideal hospital-wide $\mathrm{HH}$ events per patient day was estimated to be approximately 38 , calculated from the " 5 Moments" surveys administered by the link nurses (LNs: young nurses in charge of infection control within their ward). The ideal number of $\mathrm{HH}$ events per PD estimated for each ward ranged from 15 to 25 in the acute care wards and from 40 to 60 in the long-term wards. As $1.3 \mathrm{ml}$ of ABHR is dispended in each $\mathrm{HH}$ event, adequate hospital-wide ABHR consumption for our goal of $100 \%$ adherence was estimated to be approximately $50 \mathrm{ml} / \mathrm{PD}$. At least one bottle of ABHR was provided to each patient's room throughout the study period. The hospital has an infection control team (ICT) with 0.3 full-time equivalent (FTE) ICD throughout the study and 1.0 FTE ICN from January 2013 to the end of the study. No effective systematic $\mathrm{HH}$ initiatives had been implemented in this hospital prior to the study.

\section{Statistical methods}

An interrupted time series analysis was performed to examine the change in monthly ABHR consumption after the implementation of the $\mathrm{HH}$ initiative. The correlation between HHSAF score and ABHR consumption was assessed using Pearson's correlation coefficients. The analyses were undertaken using IBM SPSS version 24 (IBM; Armonk, New York, USA).

\section{Interventions}


We conducted an original 5-year hospital-wide HH initiative, repeating the " 5 Steps" cycle each fiscal year, without incentives, from April 2014 to March 2019. Our programme was based on the Guide to Implementation (GTI) [11], but some minor changes and local adaptations were made to match our hospital culture, as was recommended. In the GTI, the length of time recommended for each step was as follows: Step 1: 2 months, Steps 2 and 3: 3 months, Steps 4 and 5; 2 months. In our original programme, we minimized the length of time for Steps 2 and 4 by applying the data from the previous year as the baseline and the annual data as the follow-up data. In addition to translating the English tools, we prepared original posters, reminders, and educational videos to enhance comprehension. The outline of each step, determined according to the GTI, is summarized below; 201X stands for 2014 to 2018, and $201 X+1$ stands for 2015 to 2019 . The details of the activities implemented each year, based on the 5 Components, are shown in Table 1.

Table 1 Details of the activities implemented each year 


\begin{tabular}{|c|c|c|c|c|c|c|}
\hline & Activities of the initiative & Year 1 & Year 2 & Year 3 & Year 4 & Year 5 \\
\hline \multirow[t]{4}{*}{ Component 1} & Distribution of personal shoulder bags for ABHR bottles & $\times$ & $\times$ & $\times$ & $x$ & $x$ \\
\hline & Automatic ABHR dispensers at the door of each room & & $x$ & $x$ & $x$ & $x$ \\
\hline & Various types of ABHR & & $x$ & $x$ & $x$ & $x$ \\
\hline & Skin protection formula & & & & $x$ & $\times$ \\
\hline \multirow[t]{8}{*}{ Component 2} & HH leader training sessions & $x$ & & & & \\
\hline & WHO HH guideline and tool kit in all computers & $x$ & $x$ & $x$ & $x$ & $x$ \\
\hline & Regular HH training sessions for all staff & $x$ & $x$ & $x$ & & \\
\hline & Mandatory HH training sessions for all staff & & & & $x$ & $x$ \\
\hline & Original HH training video made by the ICT \& ICMs & & $x$ & $x$ & $x$ & $x$ \\
\hline & E-learning using the original training video & & & $x$ & $x$ & $x$ \\
\hline & On the job direct observation training for ICMs \& LNs & & & $x$ & $x$ & $x$ \\
\hline & Hands on training sessions & & & & & $\times$ \\
\hline \multirow[t]{9}{*}{ Component 3} & AHR consumption monitoring by ICT (monthly) & $x$ & $x$ & $x$ & $x$ & $x$ \\
\hline & AHR consumption monitoring by LNs at each ward & & $x$ & $x$ & $x$ & $x$ \\
\hline & Personal AHR consumption monitoring by LNs & & & & $x$ & $x$ \\
\hline & HH events per day survey by LNs & $x$ & $x$ & $x$ & $x$ & $x$ \\
\hline & Direct observation by ICT (twice a year per ward) & $x$ & $x$ & $x$ & $x$ & $x$ \\
\hline & Direct observation by LNs & & & $x$ & $x$ & $x$ \\
\hline & Perception survey for senior executive managers & $x$ & & & & \\
\hline & Perception survey for all staff & $x$ & & & $x$ & \\
\hline & Knowledge survey for all staff & $x$ & & $x$ & & \\
\hline \multirow[t]{6}{*}{ Component 4} & Reminders on ABHR bottles & $x$ & $x$ & $x$ & $x$ & $x$ \\
\hline & Hand wash procedure posters for all sinks & $x$ & $x$ & $x$ & $x$ & $x$ \\
\hline & Posters for each HH campaign & & $x$ & $x$ & $x$ & $x$ \\
\hline & Original 5 moments posters & & & $x$ & $x$ & $x$ \\
\hline & Original 5 moments \& ABRH procedure reminders & & & & & $x$ \\
\hline & Reminders made by LNs for each ward & & & & & $\times$ \\
\hline \multirow[t]{11}{*}{ Component 5} & Letter to the director & $x$ & & & & \\
\hline & Letters to the head of each department and ward & $x$ & & & & \\
\hline & Assigned ICMs as HH champions & $x$ & $x$ & $x$ & $x$ & $x$ \\
\hline & Selection of "HH masters" as role models & & & $x$ & $x$ & $x$ \\
\hline & HH campaign twice a year (May \& October) & $x$ & $x$ & $x$ & $x$ & $x$ \\
\hline & Campaign poster with a picture of the director & & & $x$ & $x$ & $x$ \\
\hline & Campaign poster with a picture of the staff members & & & & $x$ & $x$ \\
\hline & Institutional target & $x$ & $x$ & $x$ & $x$ & $x$ \\
\hline & Presentation sessions to share activities on $\mathrm{HH}$ & & & $x$ & $x$ & $x$ \\
\hline & Newsletters with issues on $\mathrm{HH}$ & & & $x$ & $x$ & $x$ \\
\hline & Include $\mathrm{HH}$ as a part the buddy training system & & & & & $x$ \\
\hline
\end{tabular}

LNs link nurses, ICMs infection control managers

Step 1 (April to May 201X): Facility preparedness: The infection control committee (ICC: the highest decision-making body on infection control) decided and declared the hospital-wide implementation of the WHO HH strategy, the annual aim, and the hospital-wide target amount of ABHR consumption. The ICT was assigned as the main promotion team, and the infection control managers (ICMs: the field leaders on infection control) were assigned to work as the $\mathrm{HH}$ leaders (champions) for each department and ward.

Step 2 (May 201X): Baseline evaluation: The hospital-wide ABHR consumption from the previous year was applied as the baseline. At least one direct observation session for each ward was completed by the ICT within the month. 
Step 3 (May 201X to March 201X + 1): Implementation: Tools and activities of the 5 Components were selected and adapted as described in Table 1. Hospital-wide activities were mainly led by the ICT, and local activities were mainly led by the ICMs. LNs worked with the ICMs in the nursing departments.

Step 4 (March to April 201X + 1): Follow-up evaluation: The ICT reported the annual (April 201X to March $201 X+1)$ ABHR consumption, the findings from the direct observations, and the annual HHSAF score.

Step 5 (March to April 201X + 1): Ongoing planning and review cycle: The achievement of the year and the remaining challenges were evaluated by the ICC. The target activities for the next year were planned by the ICT for continuous improvement.

\section{Results}

\section{Participants}

There were 37 physicians, 261 members of the nursing staff, 20 rehabilitation therapists, and 20 members of the recreational staff working full time in the hospital at the final month of the study. The number of workers varied within the study period but had no increasing or decreasing tendencies. The average number of monthly patient hospitalization days (patient days, PD) throughout the study period was 9970. The average for the preintervention period was 10482 PD and 9662.9 PD for the intervention period.

\section{Implementation of the initiative}

Table 2 shows the details of the 5 Steps each year. For the first 2 years, most activities were hospital-wide planned and executed by the ICT. In the following years, plans were made so that the ownership of the HH initiatives would be transferred to the ICMs, the front-line champions, to let them lead local activities.

Table 2 Details of each step in the 5-year cycle of the 5 Steps 
Year 1 (April 2014 to March 2015)

Step1\&2 The annual aim was to develop an effective system for continuous improvement, and to provide adequate $\mathrm{ABHR}$, to each point of care. The annual target amount of $\mathrm{ABHR}$ was set to $10 \mathrm{ml} / \mathrm{PD}$, as to approximately double the amount of the previous year.

Step3 The HH initiatives were planned and executed mainly by the ICT.

Step4\&5 From the direct observations, moment 1 (before touching the patient) was observed to be most missed, throughout the hospital. The target amount was achieved, but the participation of the field $\mathrm{HH}$ leaders such as ICMs and the LNs remained a challenge.

Year 2 (April 2015 to March 2016)

Step1\&2 The annual aim was to encourage the field HH leaders to take more part in the strategy. Moment 1 was focused in the promotion campaigns. The annual institutional target was set to 15ml/PD, referring to the report by Pittet et al. [1]

Step3 Initiatives were still mainly planned and executed by the ICT, but ICMs and LNs took more part, especially in the components 2 and 3.

Step4\&5 Compliance differences between individuals became apparent, by the direct observations. The target amount was achieved. The need for different approaches to match the differences of the individuals' abilities was recognized, such as defining role models, and providing adequate support to individuals having difficulties.

Year 3 (April 2016 to March 2017)

Step1\&2 This annual aim was to encourage individual support for staff with low compliance, and to promote the activities of the staff with high compliance, at each local field level. The annual institutional target was set to $25 \mathrm{ml} / \mathrm{PD}, 1 / 2$ the amount of the mean adequate ABHR consumption estimated.

Step3 Field based initiatives were reinforced, and for this purpose, many tools of component 5 were utilized.

Step4\&5 The compliance differences between the ward and departments became apparent. The target amount was $91.6 \%$ achieved. The ICC evaluated that the field level $\mathrm{HH}$ initiatives of the wards and departments with high compliances should be shared.

Year 4 (April 2017 to March 2018)

Step1\&2 The annual aim was to share effective initiatives. Moment 1 was focused again, so that sharing would be effective, as it is a common moment for everyone. The annual institutional target was set to $30 \mathrm{ml} / \mathrm{PD}, 3 / 5$ the amount of the mean adequate ABHR consumption estimated.

Step3 Effective activities were shared in ICM meetings. The ICT provided 4 weeks of intensive support to several wards experiencing difficulties.

Step4\&5 HH was found to be missed in certain routine procedures, by direct observation. The target amount was $99 \%$ achieved. The ICC evaluated that voluntary activities of the ICMs and LNs should be further encouraged.

Year 5 (April 2018 to March 2019)

Step1\&2 The annual aim was to focus on HH in the routine work of each department. The annual institutional target was set to $33 \mathrm{ml} / \mathrm{PD}$, approximately $2 / 3$ the amount of the mean adequate $\mathrm{ABHR}$ consumption estimated.

Step3 ICMs and LNs reviewed and focused on the HH moment which was tended to be missed in their everyday routine work procedures.

Step4\&5 The target amount was achieved.

ABHR alcohol-based hand rub, PD patient days, ICT infection control team, HH initiatives Hand Hygiene initiatives, ICMs infection control managers, LNs link nurses (young nurses in charge of infection control within their ward), ICC infection control committee

Table 3 shows the annual ABHR consumption and HHSAF score. The annual ABHR consumption in the preintervention period was 4.0 (ml/PD) to 4.4 and 10.4 to 34.4 in the intervention period. The HHSAF score was 117.5 (out of 500 ) in the preintervention period and 267.5 to 445 in the intervention period.

Table 3 Annual ABHR consumption and HHSAF score in each year 


\begin{tabular}{llll}
\hline & \multicolumn{1}{c}{ Intervention Year } & $\begin{array}{c}\text { Annual ABHR Consumption } \\
(\mathrm{ml} / \mathrm{PD})\end{array}$ & $\begin{array}{c}\text { HHSAF Score } \\
(/ 500)\end{array}$ \\
\hline Pre-Intervention & Year -3 (Apr-11 to Mar-12) & 4.4 & 117.5 \\
& Year -2 (Apr-12 to Mar-13) & 4.0 & 117.5 \\
\hline \multirow{3}{*}{ Intervention } & Year -1 (Apr-13 to Mar-14) & 4.2 & 117.5 \\
\hline & Year 1 (Apr-14 to Mar-15) & 10.4 & 267.5 \\
\hline & Year 2 (Apr-15 to Mar-16) & 17.7 & 310.0 \\
\hline & Year 3 (Apr-16 to Mar-17) & 22.9 & 380.0 \\
\hline & Year 4 (Apr-17 to Mar-18) & 29.6 & 410.0 \\
\hline & Year 5 (Apr-11 to Mar-19) & 34.4 & 445.0 \\
\hline
\end{tabular}

ABHR alcohol-based hand rub, HHSAF Hand Hygiene Self-Assessment Framework, $P D$ patient days

Table 4 shows the details of the HHSAF score.

Table 4 Details of the Hand Hygiene Self-Assessment Framework Score 


\begin{tabular}{|c|c|c|c|c|c|c|c|c|c|}
\hline & & Year -3 & Year -2 & Year -1 & Year 1 & Year 2 & Year 3 & Year 4 & Year 5 \\
\hline \multirow[t]{7}{*}{ Component 1} & $\begin{array}{l}1.1 \\
1.2\end{array}$ & $\begin{array}{l}10 \\
5\end{array}$ & $\begin{array}{l}10 \\
5\end{array}$ & $\begin{array}{l}10 \\
5\end{array}$ & $\begin{array}{l}30 \\
5\end{array}$ & $\begin{array}{l}50 \\
5\end{array}$ & $\begin{array}{l}50 \\
5\end{array}$ & $\begin{array}{l}50 \\
5\end{array}$ & $\begin{array}{l}50 \\
5\end{array}$ \\
\hline & 1.3 & 10 & 10 & 10 & 10 & 10 & 10 & 10 & 10 \\
\hline & 1.4 & 10 & 10 & 10 & 10 & 10 & 10 & 10 & 10 \\
\hline & 1.5 & 10 & 10 & 10 & 10 & 10 & 10 & 10 & 10 \\
\hline & 1.6 & 10 & 10 & 10 & 10 & 10 & 10 & 10 & 10 \\
\hline & add & 0 & 0 & 0 & 0 & 0 & 0 & 0 & 0 \\
\hline & sub total & 55 & 55 & 55 & 75 & 95 & 95 & 95 & 95 \\
\hline \multirow[t]{10}{*}{ Component 2} & $2.1 \mathrm{a}$ & 10 & 10 & 10 & 10 & 10 & 10 & 20 & 20 \\
\hline & $2.1 \mathrm{~b}$ & 20 & 20 & 20 & 20 & 20 & 20 & 20 & 20 \\
\hline & $2.2 \mathrm{a}$ & 0 & 0 & 0 & 5 & 5 & 5 & 5 & 5 \\
\hline & $2.2 \mathrm{~b}$ & 0 & 0 & 0 & 5 & 5 & 5 & 5 & 5 \\
\hline & $2.2 \mathrm{c}$ & 0 & 0 & 0 & 5 & 5 & 5 & 5 & 5 \\
\hline & $2.2 \mathrm{~d}$ & 0 & 0 & 0 & 5 & 5 & 5 & 5 & 5 \\
\hline & 2.3 & 0 & 0 & 0 & 0 & 0 & 15 & 15 & 15 \\
\hline & 2.4 & 0 & 0 & 0 & 0 & 0 & 0 & 0 & 15 \\
\hline & 2.5 & 0 & 0 & 0 & 0 & 0 & 0 & 10 & 10 \\
\hline & sub total & 30 & 30 & 30 & 50 & 50 & 65 & 85 & 100 \\
\hline \multirow[t]{12}{*}{ Component 3} & 3.1 & 0 & 0 & 0 & 0 & 0 & 0 & 10 & 10 \\
\hline & $3.2 \mathrm{a}$ & 0 & 0 & 0 & 0 & 0 & 5 & 5 & 0 \\
\hline & $3.2 \mathrm{~b}$ & 5 & 5 & 5 & 5 & 5 & 5 & 0 & 5 \\
\hline & $3.3 \mathrm{a}$ & 0 & 0 & 0 & 5 & 5 & 5 & 5 & 5 \\
\hline & $3.3 \mathrm{~b}$ & 0 & 0 & 0 & 0 & 0 & 0 & 0 & 0 \\
\hline & $3.3 \mathrm{c}$ & 0 & 0 & 0 & 0 & 5 & 5 & 5 & 5 \\
\hline & $3.4 \mathrm{a}$ & 5 & 5 & 5 & 10 & 10 & 10 & 10 & 10 \\
\hline & $3.4 \mathrm{~b}$ & 0 & 0 & 0 & 15 & 15 & 20 & 20 & 20 \\
\hline & $3.5 \mathrm{a}$ & 0 & 0 & 0 & 5 & 5 & 5 & 5 & 5 \\
\hline & $3.5 \mathrm{bi}$ & 0 & 0 & 0 & 0 & 7.5 & 7.5 & 7.5 & 7.5 \\
\hline & 3.5bii & 0 & 0 & 0 & 0 & 7.5 & 7.5 & 7.5 & 7.5 \\
\hline & sub total & 10 & 10 & 10 & 40 & 65 & 70 & 75 & 75 \\
\hline \multirow[t]{8}{*}{ Component 4} & $4.1 \mathrm{a}$ & 0 & 0 & 0 & 20 & 20 & 20 & 25 & 25 \\
\hline & $4.1 \mathrm{~b}$ & 5 & 5 & 5 & 5 & 5 & 5 & 5 & 15 \\
\hline & $4.1 \mathrm{c}$ & 7.5 & 7.5 & 7.5 & 7.5 & 10 & 10 & 10 & 10 \\
\hline & 4.2 & 0 & 0 & 0 & 0 & 0 & 10 & 10 & 10 \\
\hline & 4.3 & 0 & 0 & 0 & 10 & 10 & 10 & 10 & 10 \\
\hline & 4.4 & 0 & 0 & 0 & 0 & 0 & 10 & 10 & 10 \\
\hline & 4.5 & 0 & 0 & 0 & 15 & 15 & 15 & 15 & 15 \\
\hline & sub total & 12.5 & 12.5 & 12.5 & 57.5 & 60 & 80 & 85 & 95 \\
\hline \multirow[t]{18}{*}{ Component 5} & $5.1 \mathrm{a}$ & 5 & 5 & 5 & 5 & 5 & 5 & 5 & 5 \\
\hline & $5.1 \mathrm{~b}$ & 5 & 5 & 5 & 5 & 5 & 5 & 5 & 5 \\
\hline & $5.1 \mathrm{c}$ & 0 & 0 & 0 & 0 & 0 & 5 & 5 & 5 \\
\hline & $5.2 \mathrm{a}$ & 0 & 0 & 0 & 10 & 10 & 10 & 10 & 10 \\
\hline & $5.2 \mathrm{~b}$ & 0 & 0 & 0 & 0 & 0 & 0 & 0 & 0 \\
\hline & $5.2 \mathrm{c}$ & 0 & 0 & 0 & 5 & 5 & 5 & 5 & 5 \\
\hline & 5.3 & 0 & 0 & 0 & 10 & 10 & 10 & 10 & 10 \\
\hline & $5.4 \mathrm{a}$ & 0 & 0 & 0 & 5 & 5 & 5 & 5 & 5 \\
\hline & $5.4 \mathrm{~b}$ & 0 & 0 & 0 & 0 & 0 & 5 & 5 & 5 \\
\hline & $5.5 a$ & 0 & 0 & 0 & 0 & 0 & 0 & 0 & 0 \\
\hline & $5.5 \mathrm{~b}$ & 0 & 0 & 0 & 0 & 0 & 0 & 0 & 0 \\
\hline & $5.6 a$ & 0 & 0 & 0 & 0 & 0 & 5 & 5 & 5 \\
\hline & $5.6 \mathrm{~b}$ & 0 & 0 & 0 & 5 & 5 & 5 & 5 & 5 \\
\hline & $5.6 \mathrm{c}$ & 0 & 0 & 0 & 0 & 0 & 5 & 5 & 5 \\
\hline & $5.6 \mathrm{~d}$ & 0 & 0 & 0 & 0 & 0 & 5 & 5 & 5 \\
\hline & $5.6 e$ & 0 & 0 & 0 & 0 & 0 & 0 & 0 & 5 \\
\hline & $5.6 \mathrm{f}$ & 0 & 0 & 0 & 0 & 0 & 0 & 0 & 5 \\
\hline & sub total & 10 & 10 & 10 & 45 & 45 & 70 & 70 & 80 \\
\hline \multicolumn{2}{|c|}{ total HHSAF score } & 117.5 & 117.5 & 117.5 & 267.5 & 310 & 380 & 410 & 445 \\
\hline
\end{tabular}




\section{Monthly ABHR consumption}

Figure 1 shows the trend of monthly ABHR consumption. The $r$ value for the regression model was 0.958 , and the adjusted $r^{2}$ value was 0.916 . The baseline ABHR consumption in the preintervention period was estimated to be $4.3 \mathrm{ml} / \mathrm{PD}$. This was stable with no observable trend in the baseline segment. At the start of the implementation of the hospital-wide HH initiative in April 2014, an immediate increase of 4.4 $\mathrm{ml} / \mathrm{PD}$, approximately doubling the baseline ABHR consumption, was observed. Furthermore, there was a significant slope change of +0.479 (95\% confidence interval: 0359 to $0.599, p<0.001) \mathrm{ml} / \mathrm{PD}$ from before and after the implementation of the initiative. Table 5 summarizes the estimates from the segmented regression model.

Table 5 Parameter estimates, $95 \% \mathrm{Cls}$ and P-values from segmented regression model describing trend of monthly ABHR consumption

\begin{tabular}{|c|c|c|c|}
\hline & Coefficient & $95 \% \mathrm{CI}$ & $\begin{array}{l}\text { P- } \\
\text { value* }\end{array}$ \\
\hline Intercept & 4.344 & $\begin{array}{l}2.032- \\
6.656\end{array}$ & $\begin{array}{l}< \\
0.001\end{array}$ \\
\hline Baseline trend & 0.006 & $\begin{array}{l}-0.103- \\
0.115\end{array}$ & 0.919 \\
\hline $\begin{array}{l}\text { Level change from last point in the pre-implementation to the first point in the } \\
\text { implementation phase }\end{array}$ & 4.387 & $\begin{array}{l}1.499- \\
7.276\end{array}$ & 0.003 \\
\hline Slope change from pre-implementation to implementation & 0.479 & $\begin{array}{l}0.359- \\
0.599\end{array}$ & $<0.001$ \\
\hline
\end{tabular}

$A B H R$ alcohol-based hand rub, $C /$ confidence interval

The model describes trend and changes in the error rate during the pre-implementation, implementation and post-implementation phases.

${ }^{*}$ Calculated using Student's t-test.

\section{Annual ABHR consumption and HHSAF scores}

Table 3 shows the annual ABHR consumption and HHSAF score. Figure 2 shows that a significant positive correlation $(r=0.971, p<0.001)$ was found between the annual ABHR consumption and HHSAF score.

\section{Discussion}


A 5-year WHO-based HH initiative consisting of the 5 Components, the 5 Steps, and the HHSAF significantly increased $A B H R$ consumption in a nonteaching secondary hospital in Japan with long-term care wards. ABHR consumption had a significant positive correlation with the HHSAF score.

Repeating a minimum 5-year cycle of the 5 Steps of the stepwise approach and applying the 5 Components is recommended in the WHO guideline. Despite the recommendation, the majority of previous studies reporting the effect of a multimodal WHO-based $\mathrm{HH}$ programme focused only on the 5 Components. Although several studies followed the stepwise programme $[13,14]$ or a 5 -year programme $[18,19]$, to the best of our knowledge, there have been no previous studies reporting a 5-year programme with the 5 Steps. Additionally, our study is the first to report the 5-year change in the HHSAF score in a single facility.

The rationale for the importance of a 5-year programme is not given in the WHO guidelines. The target amount of ABHR consumption recommended in the guideline is $20 \mathrm{ml} / \mathrm{PD}$ (HHSAF: 3.3c), and in Pittet's study published prior to the publication of the guidelines, a period of 5 years was necessary to increase ABHR consumption from 4.1 to $20.8 \mathrm{ml} / \mathrm{PD}$ [20]. Additionally, previous studies have suggested that behavioural changes are important in the improvement of $\mathrm{HH}$ [21-23] and that this improvement took time, sometimes years. Similar results were reported from a 6-year initiative in a tertiary teaching hospital [24] and a 4-year initiative in a long-term care facility [25]. Welsh et al. identified seven key elements of behaviour change that were characteristic of success in the challenge of reducing healthcare-associated infections: organizational learning; support, resources, and accountability; communication and collaboratives; frontline staff engagement; local, focused implementation; and feedback and reinforcement [26]. Out of these elements, we mainly focused on "frontline staff engagement" and "local, focused implementation" and took many careful steps and an appropriate amount of time needed to embed them.

Component 5, "Institutional safety climate", is meant "to create an environment and perceptions that facilitate awareness-raising about patient safety issues while guaranteeing consideration of $\mathrm{HH}$ improvement as a high priority at all levels" [11], and "behavioural change" is one of its main purposes. In this component of the HHSAF, there are 2 indicators corresponding to "frontline staff engagement"; $5.4 \mathrm{a}$ : "A system for designation of $\mathrm{HH}$ champions", and 5.4b: "A system for recognition and utilization of $\mathrm{HH}$ role models".

An $\mathrm{HH}$ champion is "a person who is an advocate for the causes of patient safety and $\mathrm{HH}$ standards and takes on responsibility for publicizing a project in his/her ward and/or facility-wide". One of our first priorities in the initiative was to allocate the ICMs as the HH champions. For this purpose, we started up new systems and planned campaigns to make opportunities for them to work as active HH champions. This took 3 years altogether to put on track. In the last 2 years, the ICMs' activities shifted to leading "local, focused implementation" with the support of the LNs. The HH role model is "a person who serves as an example, whose behaviour is emulated by others". From the third year of the initiative, we started the election of "HH masters" as the $\mathrm{HH}$ role model as one of the events in the $\mathrm{HH}$ campaign month. The 
$\mathrm{HH}$ masters of each local field were elected from the frontline staff members by themselves. The number of $\mathrm{HH}$ masters gradually increased in the last 2 years. From these experiences, we retrospectively recognized that 5 years was a reasonable length of time to change systems and empower frontline staff engagement for local focused implementation.

The WHO guideline states that Step 5 of the stepwise approach is a crucial step for developing long-term plans to ensure that improvement is sustained and progresses. Many activities corresponding to each of the five components are suggested in the GTI for this step. We noticed that each component includes items indicating the "establishment of plans for the next year". We also considered one of the activities in Component 5 as an important factor; "setting annual goals" as in GTI, or "establishing an institutional target" as in 5.6b of the HHSAF. Therefore, we focused mainly on "planning specific activities" and "setting the annual institutional aim and target" in this step, based on the annual data reported in Step 4.

The annual institutional aim was decided from the findings by direct observations. We conducted direct observations constantly but did not apply any of these data as an outcome or a quantitative measure. The initiative was carried out with no additional staff reinforcement or high-tech recording devices, and obtrusive observations were not possible. The health care workers noticed that they were being observed after 5-10 minutes of observation, and adherence sharply rose, almost up to $100 \%$ in some wards. This was clearly not their usual behaviour, obviously due to the Hawthorn effect; therefore, reliable quantitative data could not be obtained. However, we were able to obtain qualitative data by "examining in detail the barriers and opportunities to increase HH compliance" [27].

The institutional target amount was decided mainly based on the annual ABHR consumption that was achieved in the previous year. After the first two years, our annual ABHR consumption nearly reached 20 $\mathrm{ml} / \mathrm{PD}$, which is the target amount stated in 3.3c of HHSAF. Thus, for years 3 to 5 , we focused on our ideal ABHR consumption with $100 \% \mathrm{HH}$ adherence, which was estimated to be approximately $50 \mathrm{ml} / \mathrm{PD}$. Therefore, we set the target for the years 3,4 , and 5 as $1 / 2(50 \%), \otimes(60 \%)$, and $\otimes(66 \%)$ our ideal amount, respectively.

We strategically evaluated the annual HHSAF score to plan specific activities for the following year. HHSAF helps to identify key issues requiring attention and the resources and tools useful for achieving them $[15,16]$. We referred to the "Template Action Plan" (TAP) [28] prepared for our HH level at the very beginning of the implementation of our initiative. However, once our $\mathrm{HH}$ initiative had started, we made our annual plans for the following year by choosing tools and activities mainly from the components that scored lowest in the HHSAF. This was effective not only because appropriate activities that were required at the moment were selected but also because it provided convincing reasons why this particular activity was chosen for the year. The frontline staff members could comprehend the meaning of each activity by explaining the details of our HHSAF score and identifying our weaknesses. We believe this empowered the local initiatives mainly led by the ICMs. Therefore, we continued to focus on improving the components with the lowest HHSAF scores for 5 consecutive years. 
We found that ABHR consumption and HHSAF score were significantly positively correlated. We expected both would increase as a result of the initiative but did not expect that the 2 variables would show such a strong correlation. A prior study from Japan [29] suggested that adherence would be improved by increasing HHSAF scores. In this study, the $\mathrm{HH}$ adherence rate obtained by direct observation and the HHSAF scores were compared between 3 Japanese hospitals. They ranked in the same order for both measurements: hospital A was first with $38.3 \% \mathrm{HH}$ adherence and a score of 335 points, followed by hospital B with $30.4 \% \mathrm{HH}$ adherence and a score of 290 points, and hospital C was last with $26.1 \% \mathrm{HH}$ adherence and a score of 232.5 points. Our findings supported their results and indicated the possibility of adopting HHSAF as a process measure in a single facility. This may be useful for some other hospitals as well, especially for those with low baseline adherence and HHSAF scores, when conducting a longterm initiative. Further reports from other hospitals and multi-centred reports are needed to confirm this.

Few previous studies have reported both ABHR consumption and the HHSAF score. In a benchmarking survey from Greece, it was reported that the median ABHR consumption was $63.6 \mathrm{ml} / \mathrm{PD}$, and the median HHSAF score was 258 points [30]. In a similar study from Italy, the average ABHR consumption was 38 $\mathrm{ml} / \mathrm{PD}$ in the ICUs and $9 \mathrm{ml} / \mathrm{PD}$ in the non-ICU wards, and the mean HHSAF score was 332.22 points [31]. Our annual ABHR consumption in the final year of the study was $34.4 \mathrm{ml} / \mathrm{PD}$, and the HHSAF score was 445 points. It may be possible to compare our results with those of the 2 previous studies; however, interfacility comparisons may reflect the different sizes and complexity in different socioeconomic settings [15].

Our study was challenging in several aspects. Although national and subnational $\mathrm{HH}$ initiatives based on the WHO HH strategy have been introduced in many countries [3,5-7], such as full-scale initiatives, had not been introduced in Japan by the time of this study, and HH initiatives were left to each hospital's own efforts. In addition, having long-term care wards with many patients on ventilators, as well as daily recreational activities, made our situation even more complex. Furthermore, similar to many other nonteaching hospitals in our country, we could not afford additional personnel for covert observations or high-tech recording devices to assess $\mathrm{HH}$ adherence. However, by tracking the ABHR consumption, together with the HHSAF score as a process measure, we were able to complete the 5-year, 5 Steps cycle, including the 5 Components. Our 5-year initiative resulted in an eight-fold increase in ABHR consumption, from 4.2 to $34.4 \mathrm{ml} / \mathrm{PD}$, which is similar to the increase reported by Pittet, from 4.1 to $30.6 \mathrm{ml} / \mathrm{PD}$, over 7 years [20].

We cannot say for certain which part of our initiative was most effective. Reviewing our present position with data on HH adherence and the HHSAF score at Step 4 gave us a bird's eye view of what we have accomplished and what is left to be done. TAPs according to the total HHSAF score are available, but even if the total scores were the same, the priorities of the activities required to make the initiative most effective would differ between facilities. Providing essential hospital-wide systems (such as staffing, education and surveillance) and ABHR to each point of care would obviously be important for most facilities when initiating an $\mathrm{HH}$ programme. However, once these are adequately provided, the actual action that would be most effective at each moment should vary greatly depending on the type of the 
facility, the level of support from the executive members, and the level of frontline involvement. We had continuous support from the executives, so we did not need to spend much effort in this respect. On the other hand, we put effort into increasing frontline staff involvement each year, as our long-term patients had many daily contacts with staff members of many different professions. The effective measures needed to increase such awareness differ between professions and are best found by the staff members themselves. For example, the ICMs created original reminders with different messages, adapting to their everyday routine work in each local field. We observed that continuous $\mathrm{HH}$ improvement depended on the awareness of each member of the frontline staff; fields with active $\mathrm{HH}$ leaders introducing new original measures continued to improve, whereas fields with low awareness experienced difficulties.

Repeating the review process for 5 consecutive years may have been the most important key of our initiative. This has become a sustainable routine for us over this period of time. Although we have reached the 'Advanced level' and our HHSAF score has only 55 points left to improve, there are still 'Leadership Criteria' to be obtained, which we are working on now. We will continue repeating this 5-step cycle to sustain our improvement in $\mathrm{HH}$ practice.

There are several limitations of this study. First, this is a report from a single Japanese hospital, providing long-term care for many patients with heavy medical needs, with no previous effective HH campaigns or initiatives. The amount of ABHR required in our hospital may be larger than in many other hospitals that do not need to set such a high target. In addition, hospitals with higher $\mathrm{HH}$ adherence at baseline may not experience such an increase in ABHR consumption.

Second, we could not continuously record direct $\mathrm{HH}$ adherence. Some amount of ABHR may have been discarded or used incorrectly. As we did not provide incentives or punishment for the amount of ABHR consumed, we assume that there was not much advantage for each staff member to discard the substance. Although we found from our direct observations that the staff members with high ABHR consumption tended to use ABHR adequately, the possibility of discarded substance and incorrect use cannot be ruled out. In addition, the amount of ABHR that was used by patients and visitors was included in the ABHR consumption. As patient involvement in hand hygiene is recommended to improve the culture and climate of $\mathrm{HH}$ and to reduce hospital-acquired infections, we included patient/visitor ABHR consumption as part of the total $\mathrm{HH}$ improvement in our hospital.

ABHR consumption monitoring is not considered the gold standard for monitoring $\mathrm{HH}$ adherence. However, conducting obtrusive direct observations, the current gold standard, continuously and daily for years is difficult for most hospitals and cannot be widely recommended in terms of feasibility. On the other hand, ABHR consumption monitoring has been officially recommended in "The surveillance procedures for small and medium sized medical facilities" since 2009 in Japan. It has also been applied by the European Centre for Disease Prevention and Control [32] for standardized surveillance purposes. Currently, many reports from European countries have adopted indirect monitoring of $\mathrm{HH}$ activity based on ABHR consumption systems, as they are good surrogates for assessing $\mathrm{HH}$ adherence $[10,30,31,33]$. A report from Africa also corroborates the use of ABHR consumption systems [34]. So long as direct 
observations are also conducted for qualitative measures and no punitive approaches are taken, $A B H R$ consumption monitoring may be reconsidered as a practical measure, especially for assessing improvement in long-term initiatives, for facilities with limited resources.

Third, the outbreaks that we experienced within this study period-a two-drug-resistant Acinetobacter baumanii outbreak in 2014 and a multiple-drug-resistant Pseudomonas aeruginosa (MDRP) outbreak in 2016-may have affected our results. Such outbreaks themselves can induce an increase in ABHR consumption, and the possibility of their influence cannot be excluded. However, the effects from these situations were expected to be temporary and limited to the ward in which the outbreak occurred. Our hospital-wide ABHR consumption continued to increase, regardless of the convergence of these outbreaks.

Fourth, the number of patient hospitalization days decreased between the preintervention period and the intervention period. This may be due to a change in the hospital policy in April 2014, which requires a referral letter from every first visit patient. It is known that poor $\mathrm{HH}$ adherence is associated with higher patient-to-staff ratios [35], so the decrease in the numbers of patients may have had some influence on increasing ABHR consumption per patient day. However, the $7.8 \%$ decrease in the mean number of patients alone could not have caused the eight-fold increase in the mean annual ABHR consumption (from 2013 to 2018), although it may have provided some positive effect.

Fifth, the HHSAF includes the amount of ABHR consumption as one of its scores. The maximum score given to the ABHR consumption is 5 points, which is $1 \%$ of the total score. $\mathrm{HH}$ adherence by direct observation is also included, with a maximum score of 30 points. Our score for direct $\mathrm{HH}$ adherence remained 20 points for the final 4 years. Altogether, our highest score for direct and indirect $\mathrm{HH}$ adherence was 25 points, which is $5 \%$ of the total score. This is not a large proportion; however, it cannot be said that the HHSAF score and ABHR consumption are completely independent variables.

\section{Conclusions}

We successfully implemented a WHO strategy-based multimodal HH initiative in a nonteaching, secondary and long-term care hospital in Japan. Working on all 5 Components, repeating the cycle of the 5 Steps for 5 years and using the HHSAF at Steps $4 \& 5$ each year resulted in a continuous increase in ABHR consumption. Our results suggested that the HHSAF score may well be considered for adoption as a process measure within a single facility, although further investigation is necessary.

\section{List Of Abbreviations}

$A B H R$ : alcohol-based hand rub; FTE: full time equivalent; GTI: Guide to Implementation; $H H$. hand hygiene; HHSAF: Hygiene Self-Assessment Framework; ICC. infection control committee; ICD: infection control doctor; ICMs: infection control managers; ICN: infection control nurse; ICT: infection control team; ICU: intensive care unit; LNs: link nurses; MDRP: multiple-drug-resistant Pseudomonas aeruginosa $\mathrm{NHO}$ : 
National Hospital Organization; PD: patient day; TAP. Template Action Plan; WHO: World Health Organization

\section{Declarations}

Ethics approval and consent to participate

Ethics approval was obtained from the NHO Shimoshizu National Hospital's Institutional Review Board for this study (authorization number 5, March, 2017). Consent to participate was waived.

Consent for publication

Not applicable.

Availability of data and materials

All the data supporting conclusions are available in the manuscript, and in the supplementary file.

Competing interests

All listed authors have no conflicts of interest to disclose.

Funding

Not applicable.

Author's contribution

MM and Y Suzuki defined the objectives of the study and led the study design and development. MM, SY and $Y$ Suzuki were faculty members that developed and delivered the $\mathrm{HH}$ initiative. IM performed data analysis and interpretation. Y Suzuki wrote the manuscript. All authors critically reviewed the manuscript and approved the final version.

Acknowledgement

The authors acknowledge all the front-line staff members of NHO Shimoshizu National Hospital, who make personal commitments to care for patients with clean hands. The authors also thank the ICC, the ICMs, and the LNs for their continuous support, and their leadership in leading local field-based initiatives.

\section{References}

1. Pittet D, Hugonnet S, Harbarth S, Mourouga P, Sauvan V, Touveneau S, Perneger TV, members of the Infection Control Programme. Effectiveness of a hospital-wide programme to improve compliance with hand hygiene. Lancet. 2000;356:1307-12. 
2. Allegranzi B, Pittet D. Role of hand hygiene in healthcare-associated infection prevention. $J$ Hosp Infect. 2009;73:305-15.

3. Stone SP, Fuller C, Savage J, et al. Evaluation of the national Cleanyourhands campaign to reduce Staphylococcus aureus bacteraemia and Clostridium difficile infection in hospitals in England and Wales by improved hand hygiene: four year, prospective, ecological, interrupted time series study. BMJ. 2012;344:e3005.

4. World Health Organization. WHO guidelines on hand hygiene in health care. Geneva, Switzerland: WHO; 2009. Available at: https://apps.who.int/iris/bitstream/handle/10665/44102/9789241597906_eng.pdf (Last accessed January 2020).

5. Moro ML, Morsillo F, Nascetti S, Parenti M, Allegranzi B, Pompa MG, Pittet D. Determinants of success and sustainability of the WHO multimodal hand hygiene promotion campaign, Italy, 20072008 and 2014. Euro Surveill. 2017;22(23):pii=30546.

6. Wetzker W, Walter J, Bunte-Schönberger K, Schwab F, Behnke M, Gastmeier P, Reichardt C. Hand Rub Consumption Has Almost Doubled in 132 German Hospitals Over 9 Years. Infect Control Hosp Epidemiol. 2017;38:870-2.

7. Grayson ML, Stewardson AJ, Russo PL, Ryan KE, Olsen KL, Havers SM, et al. Effects of the Australian National Hand Hygiene Initiative after 8 years on infection control practices, health-care worker education, and clinical outcomes: a longitudinal study. Lancet Infect Dis. 2018;18:1269-77.

8. Sakihama T, Honda H, Saint S, Fowler KE, Shimizu T, Kamiya T, et al. Hand hygiene adherence among health care workers at Japanese hospitals: a multicenter observational study in Japan. J Patient Saf. 2016;12:11-7.

9. Buet A, Cohen B, Marine M, Scully F, Alper P, Simpser E, Saiman L, Larson E. Hand hygiene opportunities in pediatric extended care facilities. J Pediatr Nurs. 2013;28:72-6.

10. Szabó R, Morvai J, Bellissimo-Rodrigues F, Pittet D. Use of hand hygiene agents as a surrogate marker of compliance in Hungarian long-term care facilities: first nationwide survey. Antimicrob Resist Infect Control. 2015;4:32-8.

11. World Health Organization. Guide to implementation: a guide to the implementation of the WHO multimodal hand hygiene improvement strategy. Geneva, Switzerland: WHO; 2009. Available at: https://www.who.int/gpsc/5may/tools/WHO_IER_PSP_2009.02_eng.pdf?ua=1 (Last accessed January 2020).

12. Gould DJ, Moralejo D, Drey N, Chudleigh JH, Taljaard M. Interventions to improve hand hygiene compliance in patient care. Cochrane Database of Systematic Reviews 2017, Issue 9. Art. No.: CD005186. DOI: 10.1002/14651858.CD005186.pub4.

13. Allegranzi B, Sax H, Bengaly L, Richet $H$, Minta DK, Chraiti MN, et al. Successful implementation of the World Health Organization hand hygiene improvement strategy in a referral hospital in Mali, Africa. Infect Control Hosp Epidemiol. 2010;31:133-41. 
14. Chen JK, Wu KS, Lee SS, Lin HS, Tsai HC, Li CH, Chao HL, Chou HC, Chen YJ, Huang YH, Ke CM, Sy CL, Tseng YT, Chen YS. Impact of implementation of the World Health Organization multimodal hand hygiene improvement strategy in a teaching hospital in Taiwan. Am J Infect Control. 2016;44:222-7.

15. World Health Organization. Hand Hygiene Self-Assessment Framework 2010: introduction and user instructions. Geneva, Switzerland: WHO; 2010. Available at:

https://www.who.int/gpsc/country_work/hhsa_framework_October_2010.pdf?ua=1 (Last accessed January 2020).

16. Stewardson AJ, Allegranzi B, Perneger TV, Attar H, Pittet D. Testing the WHO Hand Hygiene SelfAssessment Framework for usability and reliability. J Hosp Infect. 2013;83:30-5.

17. Kilpatrick C, Tartari E, Gayet-Ageron A, Storr J, Tomczyk S, Allegranzi B, et al. Global hand hygiene improvement progress: two surveys using the WHO hand hygiene self-assessment framework. J Hosp Infect. 2018;100:202-6.

18. Al-Tawfiq JA, Abed MS, Al-Yami N. Promoting and sustaining a hospital-wide, multifaceted hand hygiene program resulted in significant reduction in health care-associated infections. Am J Infect Control. 2013;41:482-6.

19. Chun JY, Seo HK, Kim MK, Shin MJ, Kim SY, Kim M, Kim CJ, Song KH, Kim ES, Lee H, Kim HB. Impact of a hand hygiene campaign in a tertiary hospital in South Korea on the rate of hospital-onset methicillin-resistant Staphylococcus aureus bacteremia and economic evaluation of the campaign. Am J Infect Control. 2016;44:1486-91.

20. Pittet D, Sax H, Hugonnet S, Harbarth S. Cost implications of successful hand hygiene promotion. Infect Control Hosp Epidemiol. 2004;25:264-6.

21. Larson E, Quiros D, Lin S. Dissemination of the CDC's Hand Hygiene Guideline and impact on infection rates. Am J Infect Control. 2007;35:666-75.

22. Marra AR, Guastelli LR, de Araujo CM, dos Santos JL, Lamblet LC, Silva M. Positive deviance: a new strategy for improving hand hygiene compliance. Infect Control Hosp Epidemiol. 2010;31:12-20.

23. Marra AR, Guastelli LR, de Araujo CM, dos Santos JL, Filho MA, Silva CV. Positive deviance: a program for sustained improvement in hand hygiene compliance. Am J Infect Control. 2011;39:1-5.

24. Mayer J, Mooney B, Gundlapalli A, Harbarth S, Stoddard GJ, Rubin MA. Dissemination and sustainability of a hospital-wide hand hygiene program emphasizing positive reinforcement. Infect Control Hosp Epidemiol. 2011;32:59-66.

25. Larson E, Murray M, Cohen B, Simpser E, Pavia M, Jackson O, Jia H, Hutcheon RG, Mosiello L, Neu N, Saiman L. Behavioral Interventions to Reduce Infections in Pediatric Long-term Care Facilities: The Keep It Clean for Kids Trial. Behav Med. 2018;44:141-50.

26. Welsh CA, Flanagan ME, Hoke SC, Doebbeling BN, Herwaldt L; Agency for Healthcare Research and Quality Hospital-Acquired Infections Collaborative. Reducing health care-associated infections (HAls): lessons learned from a national collaborative of regional HAl programs. Am J Infect Control. 2012;40:29-34. 
27. Jeanes A, Coen PG, Wilson AP, Drey NS, Gould DJ. Collecting the data but missing the point: validity of hand hygiene audit data. J Hosp Infect. 2015;90:156-62.

28. World Health Organization. Template Action Plan for WHO Framework Inadequate/Basic Geneva, Switzerland: WHO; 2012. Available at: https://www.who.int/gpsc/5may/PSP_GPSC1_InadequateBasicWeb_Feb-2012.pdf?ua=1 (Last accessed January 2020).

29. Sakihama T, Kayauchi N, Kamiya T, Saint S, Fowler K, Ratz D, Sato Y, luchi R, Honda H, Tokuda Y. Assessing sustainability of hand hygiene adherence 5 years after a contest-based intervention in 3 Japanese hospitals. Am J Infect Control. 2020;48:77-81.

30. Kritsotakis El, Astrinaki E, Messaritaki A, Gikas A. Implementation of multimodal infection control and hand hygiene strategies in acute-care hospitals in Greece: A cross-sectional benchmarking survey. Am J Infect Control. 2018;46:1097-103.

31. Bert F, Giacomelli S, Ceresetti D, Zotti CM. World Health Organization Framework: Multimodal Hand Hygiene Strategy in Piedmont (Italy) Health Care Facilities. J Patient Saf. 2019;15:317-321.

32. European Centre for Disease Prevention and Control. Point Prevalence Survey of HealthcareAssociated Infections and Antimicrobial Use in European Acute Care Hospitals. Stockholm: ECDC; 2013. Available from: https://ecdc.europa.eu/sites/portal/ files/media/en/publications/Publications/healthcare-associated-infections-antimicrobial-usePPS.pdf. (Last accessed June 2019).

33. Hansen S, Schwab F, Gastmeier P, PROHIBIT study group, Pittet D, Zingg W, Sax H, Gastmeier P, Hansen S, Grundmann H, van Benthem B, van der Kooi T, Dettenkofer M, Martin M, Richet H, Szilágyi E, Központ OE, Heczko PB, Holmes A, Kyratsis Y, Ahmad R, Allegranzi B, Magiorakos A, Cookson B, Wu AW. Provision and consumption of alcohol-based hand rubs in European hospitals. Clin Microbiol Infect. 2015;21:1047-51.

34. Pfäfflin F, Tufa TB, Getachew M, Nigussie T, Schönfeld A, Häussinger D, Feldt T, Schmidt N. Implementation of the WHO multimodal Hand Hygiene Improvement Strategy in a University Hospital in Central Ethiopia. Antimicrob Resist Infect Control. 2017;6:3.

35. Kuzu N, Ozer F, Aydemir S, Yalcin AN, Zencir M. Compliance with hand hygiene and glove use in a university-affiliated hospital. Infect Control Hosp Epidemiol. 2005;26:312-5.

\section{Figures}




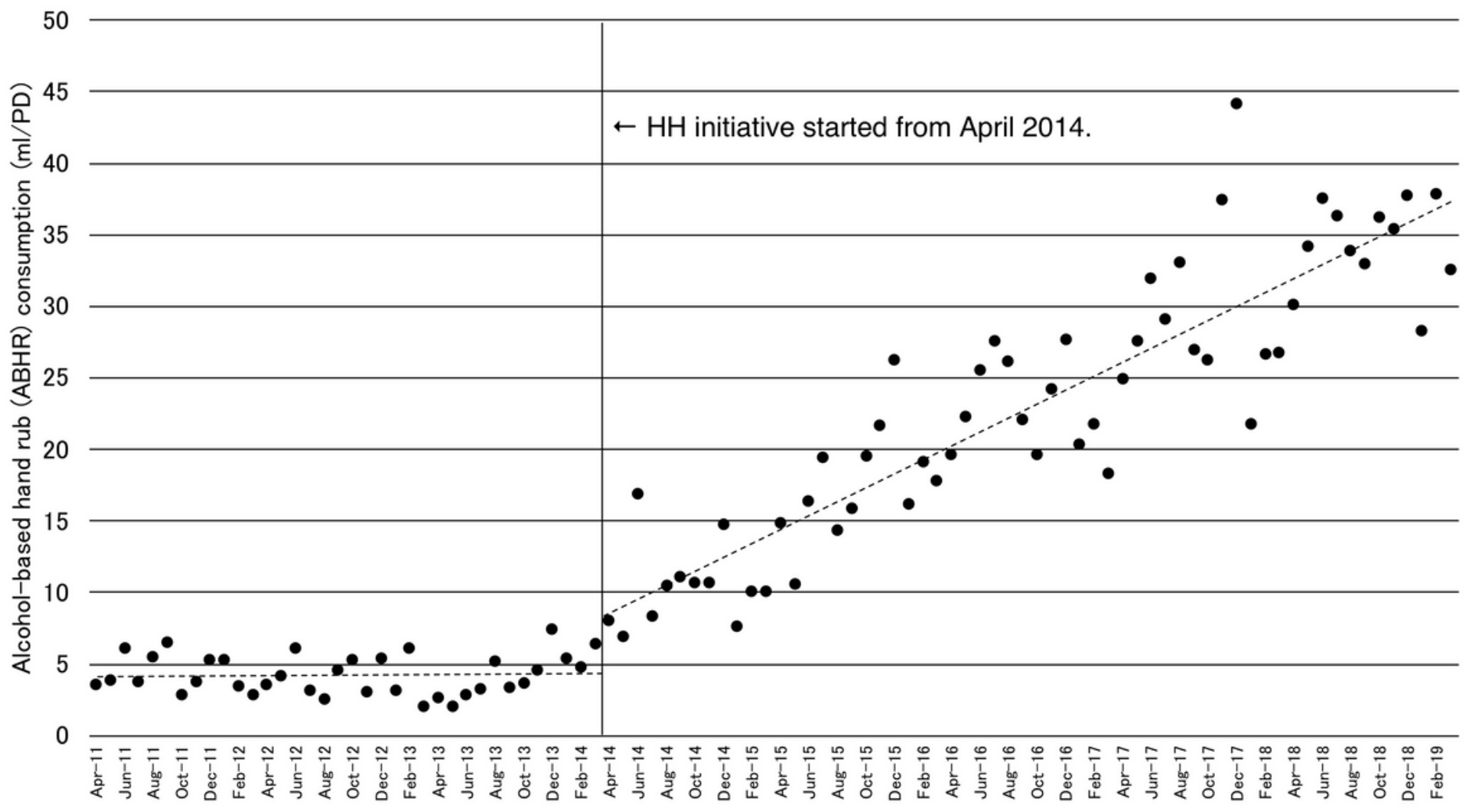

Figure 1

Trends change in $A B H R$ consumption before and after the implementation of the $\mathrm{HH}$ initiative. $\mathrm{ABHR}$ alcohol-based hand rub, $\mathrm{HH}$ initiatives Hand Hygiene initiatives, PD patient day. 


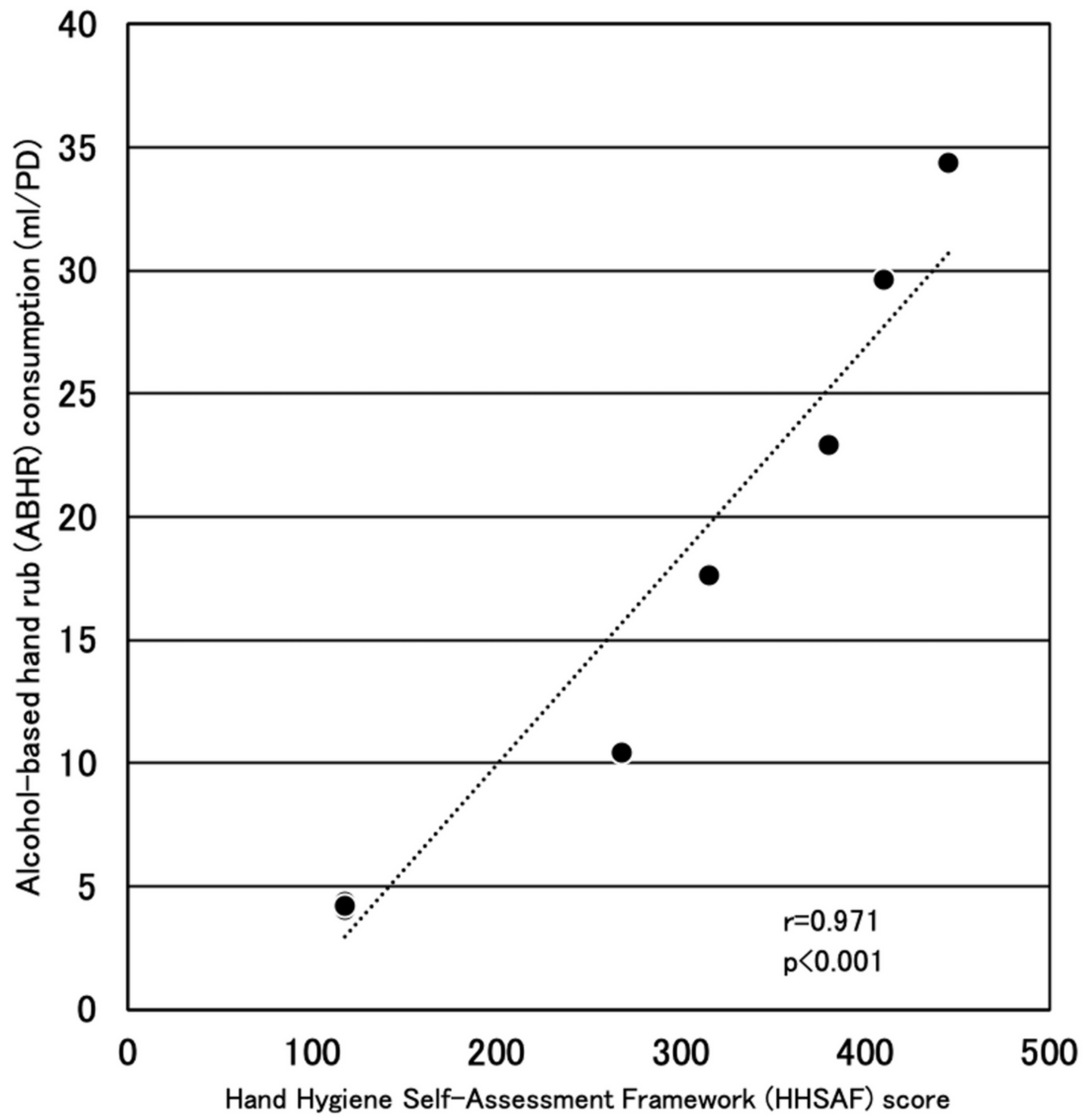

Figure 2

Relationship between annual ABHR consumption and HHSAF score. ABHR alcohol-based hand rub, HHSAF Hand Hygiene Self-Assessment Framework, PD patient day.

\section{Supplementary Files}


This is a list of supplementary files associated with this preprint. Click to download.

- Supplementaryfile.xlsx 